\title{
Mulheres, sindicato e organização política nas greves de 1917 em São Paulo
}

Women, Unions and Political Organization in the Strikes of 1917 in São Paulo

\author{
Glaucia Cristina Candian Fraccaro*
}

\section{Resumo}

Este artigo apresenta elementos da participação das mulheres nas Greves de 1917, em São Paulo. A mobilização que atingiu toda a cidade e transformou o movimento operário contou com grande número de trabalhadoras em suas fileiras. No entanto, sua baixa participação nos sindicatos e nas organizações políticas nem sempre configurou uma total indiferença de gênero nas barganhas coletivas ou manteve intacta a ordem social e econômica. Participação sindical, bases de acordo e legislação social foram questões demarcadas pelas demandas das trabalhadoras conformando uma noção de justiça social que deveria tratar diretamente da experiência das mulheres trabalhadoras.

Palavras-chave: mulheres; greves; direitos.

\begin{abstract}
This paper brings some issues regarding women's role during 1917's Strikes in São Paulo. The mobilization, which counted with a great number of women, reached the whole city and made significant changes in labor movement. Despite the low female enrolment in trade unions and political organization, women's demand took part in general claims. The enrolment in trade unions, basis of agreement and social legislation were featured by female workers in order to contest the meanings of social justice.
\end{abstract} Keywords: women; strikes; social rights.

Em 2009, a ministra da Secretaria de Políticas para Mulheres, Nilcéia Freire, encaminhou à Comissão de Constituição, Justiça e Cidadania um anteprojeto de lei que previa a efetivação da igualdade entre homens e mulheres nas relações de trabalho. No texto da proposição legislativa n. 6653, a ministra propôs regras pertinentes ao equilíbrio entre as responsabilidades familiares e profissionais e medidas de incentivo às empresas para a adoção de planos de igualdade de gênero. Com a aprovação dessa lei, o governo brasileiro pretendia

\footnotetext{
* Pontifícia Universidade Católica de Campinas (PUC-Campinas). Campinas, SP, Brasil. galufraccaro@ gmail.com
} 
ampliar o exercício do Estado Democrático de Direito e a "plenitude dos direitos de cidadania", o que considerava primado da igualdade. $\mathrm{Na}$ exposição de motivos, a ministra remontou às origens da questão: "A Assembleia Nacional Constituinte (1986-1988) acolheu o clamor do movimento de mulheres, cujas vozes ecoavam desde os primórdios da República”. Por que existe, no século XXI, uma proposição legislativa para a igualdade entre mulheres e homens? A Secretaria de Políticas para as Mulheres havia encampando a proposta de criar uma lei como essa com o objetivo de interferir em indicadores sociais desiguais: os censos e pesquisas domiciliares de 2009 apontavam que a diferença salarial por sexo atingia $30 \%$, que havia poucas mulheres trabalhando em postos mais remunerados, e que a divisão do trabalho dentro das casas era desequilibrada, relegando a maior parte das tarefas domésticas às mulheres.

O projeto de lei, além de mostrar que a igualdade das mulheres no mundo do trabalho ainda é uma questão importante e atual, também trouxe o argumento de que a luta por essa igualdade, consagrada nos anos 1980, remetia ao final do século XIX, quando a República brasileira assistia à campanha pelo voto feminino e dava seus primeiros passos para consolidar uma legislação social. Muito antes da proposição legislativa de 2009, arquivada em 2015 pelo presidente da Câmara, deputado Eduardo Cunha, o Decreto 21.417-A, de 17 de maio de 1932, estipulou a licença-maternidade, proibiu a desigualdade salarial e o trabalho noturno das mulheres. Esse decreto fez parte do Código do Trabalho, previsto e implementado por Getúlio Vargas, embora uma série de pressões sociais por esse tipo de regulação datasse ainda do começo da República, principalmente das Greves de 1917. A necessidade de leis para igualdade e seus efeitos fazem parte da história dos direitos sociais e da vida de muitas mulheres e homens do Brasil.

Este artigo pretende compreender, com base nas Greves de 1917, em que termos se deu a participação de mulheres na organização social e nos sindicatos, já reconhecida em muitas pesquisas, sob o ponto de vista da agenda da igualdade e das condições de trabalho. A pergunta que move este texto, como ironizou Alice Kessler-Harris, é uma formulação que bem poderia ser de autoria de homens sindicalizados, já que, na opinião da historiadora americana, outro conjunto de respostas se abre se a indagação se altera: "quando paramos de perguntar por que as mulheres não se organizaram, somos levados a questionar como as mulheres pensam a organização e como os sindicatos podem ser excludentes" (Kessler-Harris, 2007). ${ }^{1}$

Se um enredo favorito da história é a descoberta da transformação, as mulheres estariam, supostamente, excluídas de suas páginas por perturbar 
menos a ordem estabelecida. Pensar a história das mulheres conduz, portanto, a considerar a história das relações entre os sexos de modo a elucidar com riqueza a perspectiva de "permanências e mudanças, das relações do sujeito e do objeto, da cultura e da natureza, do público e do privado". É Michelle Perrot quem se debruça sobre os silêncios das mulheres na história para afirmar que, no mundo do trabalho, a categoria "gênero" parece mais pertinente e eficaz em todas as suas dimensões. A divisão de papéis e as funções sociais que emergem de uma conformação biológica - "uma vagina para receber, um ventre para carregar e seios para amamentar" - marcariam o destino delas: "nenhum lugar além do lar" (Perrot, 2005).

A suposta passividade das mulheres, por estarem, hipoteticamente, ausentes das grandes greves, por serem excluídas de sindicatos e partidos, não é suficiente para compreendermos por que o mundo mudou tanto para as mulheres ao longo do século XX. Não é possível afirmar categoricamente que a ausência numérica de mulheres nas instituições tenha desembocado numa total indiferença de gênero nas barganhas coletivas e políticas ou tenha mantido intacta a ordem social e econômica (Cobble, 2004). Este artigo pretende analisar a participação das mulheres nas Greves de 1917 considerando que boa parte do repertório de direitos sociais que emerge dos conflitos sopesará a experiência das trabalhadoras, a exemplo do Decreto de 1932.

\section{ORganizaÇão SINDICAL}

Com origem étnica variada - em 1920, mais da metade ainda eram estrangeiros -, trabalhadores e trabalhadoras poderiam se organizar em sociedades de socorro mútuo, já que, antes da República, as leis lhes negavam outras formas de arregimentação. Sindicatos operários, pluriprofissionais ou por ofício, passaram a ser mais comuns depois de 1890 e, ainda que convivessem com as organizações mutuais, tornaram-se a base da organização operária na Primeira República. As tentativas de uma organização sistemática eram mais constantes do que a própria duração das federações (Batalha, 2000). A Federação Operária do Rio de Janeiro, formada em 1906 por um breve período, retornou às atividades entre 1907 e 1910, e foi depois novamente reorganizada entre 1912 e 1917, quando foi fechada pela polícia. A mais conhecida das centrais sindicais desse período foi a Confederação Operária Brasileira, criada pelo $1^{\circ}$ Congresso Operário Brasileiro de 1906, com atuação mais presente entre 1913 e 1915. Outros esforços parecidos esbarraram no mesmo obstáculo, de acordo com Cláudio Batalha: "a ausência de uma base nacional real" (Batalha, 2000). Nesse 
quadro, não é impossível encontrar algumas mulheres que se envolveram na organização popular, mas não raro suas trajetórias são entendidas como casos excepcionais a destoarem de um mundo sindical tomado por homens, que as manteve distantes das agremiações por quase todo o século XX.

No entanto, é preciso ir além das barreiras colocadas pelos próprios sindicatos para compreender que a presença de mulheres na organização política não pode ser entendida como excepcionalidade. Com vistas a entender a baixa sindicalização e focalizar suas demandas e disputas, é preciso abordar a presença das mulheres no movimento operário tendo em vista suas pautas específicas e a forma como essas reivindicações se inseriam na atuação política mais ampla da classe. É preciso, também, verificar como as tensões do movimento de trabalhadores e a vida política, em São Paulo, afetaram a busca pelos direitos das mulheres.

\section{7, São PAULO}

O ano de 1917 é um marco na história da classe trabalhadora da cidade de São Paulo, como de outras grandes cidades de diversas partes do mundo. A observação desses momentos de inflexão, no entanto, requer o reconhecimento de que nem tudo começa em junho daquele ano. A organização operária e sindical e períodos grevistas culminaram, em 1905, na formação da Federação Operária de São Paulo. A pesquisa de Luigi Biondi demonstrou as intrincadas relações sociais que envolviam identidade étnica e política e que compõem o cenário sindical na cidade de São Paulo nas primeiras décadas do século XX, considerando a massa de imigrantes italianos que faziam parte da mão de obra fabril e as diversas correntes com as quais se identificavam e se organizavam, anarquistas ou socialistas (Biondi, 2011; Hall, 2010). A predominância do sindicalismo revolucionário, demonstrada por Edilene Toledo desde os últimos anos do século XIX, não apagou a coexistência de outras perspectivas políticas - a autora revela as disputas e dinâmicas da história da classe trabalhadora que havia sido contada como sendo hegemonicamente anarquista (Toledo, 2004).

Entre sociedades mutualistas, combativas, políticas e de identidade étnica, organizou-se o Comitê Popular de Agitação contra a exploração das crianças, fundado em março de 1917. Por meio de enquetes, reuniões e palestras, procurava revelar as torpes relações de trabalho a que os menores estavam sujeitos: jornadas extenuantes e graves acidentes. $\mathrm{O}$ grupo não se reuniu sem motivo. Até mesmo nas notícias de jornais era comum encontrar casos como o de José, de 12 anos, que teve o braço esmagado por uma máquina amassadeira da 
fábrica de biscoitos A Fidelidade, e Henrique Guido, de 8 anos, que teve os dedos decepados numa oficina da Barra Funda. ${ }^{2}$

A organização em torno do comitê colocava em jogo a retomada da organização sindical dos trabalhadores em São Paulo, e nele apareciam as dissensões internas e as diferentes visões que se formavam sobre a organização da classe trabalhadora. Socialistas e anarquistas não estavam de acordo quanto ao andamento do comitê contra a exploração de crianças - os primeiros defendiam que o Estado deveria tomar providências e apoiavam a efetivação de leis para regular o trabalho de menores, enquanto os anarquistas rejeitavam a intervenção do poder público e concentravam a atividade em agitação e propaganda (Biondi, 2011).

A distinção de posições, ao menos nesse momento, não seria capaz de refrear a organização que tomava corpo entre mulheres e homens do trabalho das fábricas. Trabalhadores de diversas correntes se organizavam contra a exploração desmedida e a carestia, a inflação e a baixa qualidade dos gêneros alimentícios. Para Michael Hall, os conflitos, que estavam tomando grandes proporções, mais se assemelhavam a motins contra a fome (Hall, 1975). Depois dos festivais do dia do trabalho de 1917, formou-se a Liga Operária do Belenzinho, dirigida por Maria Antônia Soares, ${ }^{3}$ irmã de Florentino de Carvalho, escritor e anarquista. Logo em seguida, a liga se transformou na comissão organizadora de uma federação paulista, a União Geral dos Trabalhadores, que se filiaria à Confederação Brasileira Operária. Menos do que uma forma anarquista de organização a negar as corporações de ofício, a formação de ligas nos bairros se mostrava como uma maneira de concentrar numa mesma dinâmica grupos diferentes de trabalhadores. Não raro, as ligas de bairro congregariam pessoas de uma mesma fábrica, como a Liga Operária da Mooca, fundada logo em seguida, cujos membros, em sua maior parte, eram mulheres empregadas no Cotonifício Crespi (Biondi, 2011).

Antes mesmo de explodir o protesto social de junho de 1917, a organização sindical já estava em andamento. As greves operárias que eclodiram em São Paulo em junho de 1917 se tornariam o símbolo não só da miséria social vivida pela classe trabalhadora no período, mas também de rebeldia e revolta de mulheres e homens que compunham a força de trabalho da cidade, e dos anos de guerra mundial que já pesavam sobre todos. Os conflitos propagaram-se a partir do Cotonifício Crespi, com cerca de 2 mil trabalhadores, e em pouco tempo congregaram 50 mil pessoas numa cidade de $400 \mathrm{mil}$ habitantes (Biondi, 2009). A princípio, as greves foram impulsionadas por anos seguidos de inflação, e, no contexto de carestia, as reivindicações eram 
a abolição de multas contra os trabalhadores, a regulamentação do trabalho de menores e a supressão do pagamento da comissão pró-pátria. ${ }^{4}$ Duas operárias ficaram encarregadas de dirigir um pequeno grupo, cuja tarefa era a de informar a imprensa sobre o estopim dos conflitos visitando as redações dos jornais da capital. ${ }^{5}$

Naquele momento, as mulheres ocupavam quase $34 \%$ da força de trabalho, e no setor têxtil o número de empregadas superava o de homens (Pena, 1981). Na Fábrica de Fósforos Pauliceia, os trabalhadores chegavam a receber diárias de 4 mil réis, mas havia lá cem mulheres empregadas que não recebiam mais que 1.800 réis por dia. ${ }^{6}$ As condições de trabalho, generalizadamente péssimas, e a mão de obra infantil, também largamente utilizada, não teriam fim com a vitória da greve: em 1925, as trabalhadoras da fábrica Mariângela afirmaram que os homens recebiam de 7 a 9 mil réis por dia e as mulheres, entre 4 mil e 5.500 réis; as crianças, a maior parte delas, meninas, na tarefa de cuidar das espulas (grandes carretéis de linha que abastecem os teares), ganhavam entre 1.500 e 2 mil réis (Hall; Pinheiro, 1979).

Com a deflagração da greve, a polícia igualmente se mobilizou e as pressões, muitas vezes exercidas a pedido dos donos de fábricas, resultaram em investigação de ativistas, repressão de algumas lideranças, fechamento de reuniões e até assassinato de trabalhadores, como o de José Gimenez Martinez, sapateiro, anarquista, com 21 anos. Em meio aos conflitos, o secretário de Justiça do Estado de São Paulo, Elói Chaves, estabeleceu diálogo direto com os donos de fábrica, ao passo que se formava o Comitê de Defesa Proletária, que coordenava a greve geral e era composto por militantes político-sindicais; não faziam parte dele as comissões de grevistas (Biondi, 2011). Das pautas conduzidas pelo Comitê de Defesa Proletária constavam: abolição do trabalho noturno para as mulheres, direito de greve e reunião, abolição da exploração do trabalho de menores de 14 anos, ganhos salariais, jornada de trabalho de 8 horas, acesso a alimentação e moradia. ${ }^{7}$ Pela primeira vez a abolição do trabalho noturno das mulheres aparecia como reivindicação, nas greves de 1917.

A imprensa passava a falar do trabalho das mulheres em fábricas com mais assiduidade. A maior parte dos editoriais abordava o assunto sem remeter ao que pensavam as mulheres presentes nos protestos que se iniciavam. Para O Combate, a questão tinha uma face higiênica e outra financeira. Defendia a limitação do trabalho das mulheres para evitar o "sofrimento da prole" e porque, "sem a concorrência das mulheres e das crianças", os homens encontrariam mais postos de trabalho, mais bem remunerados. Para o periódico, "as mulheres se prestam mais facilmente às explorações dos patrões que lhes 
pagam misérias a que operários conscientes não se sujeitariam”, acusando-as de "fura-greves". Por esses motivos, defendiam abertamente que o governo cumprisse a lei que proibia o trabalho de menores de 14 anos e que velasse pelo impedimento de as trabalhadoras "se entregarem aos serviços noturnos". ${ }^{8} \mathrm{O}$ artigo se referia aos Códigos Sanitários aprovados e reformados - em 1893 e 1896 respectivamente - no estado de São Paulo, e que estabeleciam a proibição de menores trabalharem em fábricas, mas que, por falta de fiscalização e inspeção, eram cotidianamente burlados e ignorados. ${ }^{9}$ A falta de familiaridade e de aplicação do Código Sanitário apareceu até mesmo na fala do presidente do estado, Altino Arantes. No calor dos protestos sociais, ele teria afirmado "não estar bem lembrado se as reclamações dos operários sobre o trabalho noturno de menores de 18 anos tinham apoio na lei". ${ }^{10}$

Depois da intermediação da imprensa, o Comitê de Defesa Proletária, o poder público e os empresários conseguiram atingir uma base de acordo que consistia em: reconhecimento do direito de reunião, aumento salarial de $20 \%$, libertação de presos e proibição de demissão de grevistas. As agitações não estavam terminadas e ainda se alastrariam por Campinas, Santos e Jundiaí.

A manhã de 17 de outubro de 1917 nasceu com uma paralisação numa das fábricas de Matarazzo, a Mariângela. A notícia veiculada informava que as operárias do ramo têxtil reivindicavam aumento de $20 \%$ dos salários em atitude pacífica. O padrão de mulheres "fura-greves" que o jornal havia tentando formular não encontrava respaldo nas suas próprias páginas. Os "fura-greves" denunciados na paralisação da Malharia Leão eram homens que se alistaram nos postos de trabalho deixados por mulheres e meninas, em greve por serem sistematicamente abusadas pelo dono da fábrica que, por sua vez, já havia respondido a processo por desonra na polícia. ${ }^{11}$

No mesmo ano, a fábrica Mariângela voltou a paralisar. Dessa vez, queixavam-se do mestre de oficinas que, de acordo com as mais de mil mulheres em piquete, "as desrespeita até na hora do serviço", tendo ele perdido "a devida compostura". Diante da recusa do gerente em demitir o capataz, as operárias mantiveram o protesto até a chegada do delegado, que mandou a cavalaria para a frente da fábrica. As operárias, então, debandaram e não houve emprego da violência, de acordo com o relato do jornal, "como aliás, era natural, tratando-se de moças". ${ }^{12}$ A Liga Operária do Belenzinho, que reunia o pessoal da fábrica de tecidos Matarazzo, manteve-se mobilizada ao fim das greves de julho e decidiu lutar até que fosse demitido o revistador de peças do referido estabelecimento, conquistada a liberdade para um operário preso e permitida a falta no emprego por motivo de doença, embora com perda dos vencimentos. Exigia 
ainda que ninguém fosse demitido por fazer greve e "que os patrões tratem os operários e as operárias com respeito”. A participação ativa das mulheres no andamento da organização se estendeu para além de julho e era constantemente atestada:

É certo que há uma greve de operários na fábrica de tecidos de propriedade de F. Matarazzo, neste bairro e que os grevistas todos, na maioria mulheres, se utilizam da nossa sede para as suas assembleias, a fim de tratarem dos seus interesses, mas também não é menos certo que eles, até o presente, se têm conservado em atitude pacífica, sem a menor demonstração de hostilidade contra quem quer que seja. ${ }^{13}$

No Belenzinho, o delegado proibiu a realização de um encontro da liga, mas acabou consentindo em que apenas mulheres entrassem na sede sob a vigilância de um subdelegado e dois secretas. A participação das operárias era parte fundamental na negociação dos conflitos, a ponto de $O$ Combate assim avaliar o ocorrido: "A imposição de só reunirem mulheres foi uma manobra que o delegado Bandeira de Mello pôs em prática imaginando que elas eram fracas e inconscientes, no que de todo se enganou". ${ }^{14}$

As vitórias do movimento grevista, firmadas na base de acordo com empresários e poder público, atraiu mais adesões ao movimento, até mesmo aqueles provenientes de pequenas e médias fábricas. A nova Federação Operária do Estado de São Paulo foi criada, então, dias depois, em 26 de agosto de 1917, composta por ligas de bairro, associações por categoria e sindicatos (Biondi, 2011). Os fins imediatos da federação que se reestruturava foram estipulados assim: que encarregados e gerentes respeitassem todos os operários, que se lutasse "pela igualdade dos salários das mulheres ao dos homens, e que lhes sejam garantidos o mesmo quando, no último período da gravidez ou após o parto, forem obrigadas a deixar de trabalhar", que se proibisse a ocupação de menores de 14 anos. A federação também incorporou a reivindicação de pagamento de indenizações para acidentes de trabalho, regulação da jornada de trabalho em 8 horas, extinção das horas extras e a supressão do trabalho noturno, salvo nos vapores, hospitais ou outros estabelecimentos em que seja de absoluta necessidade pública. ${ }^{15}$ Dessa vez, a proibição do trabalho noturno aparecia como reivindicação a atingir homens e mulheres.

As bases da federação operária tinham sido moldadas a partir das resoluções dos congressos que precederam a reorganização da entidade. Em 1906, o sindicalismo revolucionário havia prevalecido nas resoluções vitoriosas em 
debates sobre a destruição do Estado e os perigos do reformismo (Hall, 1975). Sem mulheres no rol de militantes, os participantes, ao se questionarem sobre "como regulamentar o trabalho feminino", consideraram que a principal causa da exploração das operárias era a falta de "coesão e solidariedade" entre elas e que, para enfrentar o problema, deveriam empenhar esforços para organizar as mulheres e torná-las companheiras de luta. É preciso dizer que não trataram da condição da mulher que trabalha ou da regulamentação do seu trabalho, concentrando-se na organização sindical. Cabe ressaltar que o apelo para que o movimento exigisse a jornada de 8 horas de trabalho motivou grandes greves na cidade de São Paulo (Hall; Pinheiro, 1979). O assunto das mulheres não voltou à tona no Congresso Operário de 1913, que reafirmaria os princípios do sindicalismo revolucionário.

A emergência do tema da normalização do trabalho das mulheres, nos momentos de organização sindical e grevista, apareceu numa pauta difusa. Era difícil silenciar ou apagar a presença delas como parte da força de trabalho e do movimento operário, mas a agenda proveniente dos momentos de mobilização não era homogênea. Mesmo em correntes opostas, algumas reivindicações ganhavam espaço, como a jornada de 8 horas e o problema dos altos preços dos alimentos. A bandeira "salário igual para trabalho igual" constava dos princípios do Comitê de Defesa Proletária e, na Federação Operária de São Paulo, figurava uma proposta de licença depois do parto e a proibição do trabalho noturno de mulheres. Entretanto, ao nos determos nas reivindicações das numerosas paredes e piquetes que duraram poucos dias ou algumas horas depois de julho de 1917, é possível notar que as queixas mais comuns, mesmo em fábricas com grande número de mulheres empregadas, eram relacionadas a abusos dos mestres e aumento de salários. A greve do dia 30 de junho de 1917, na fábrica Mariângela, reivindicava aumento de salários, fim das condições ruins de trabalho e o fim do abuso por parte dos feitores (Wolfe, 1993). As denúncias de abuso se tornaram frequentes na imprensa operária. "Conduta suspeita" para com as mulheres por parte de encarregados, baixos salários e jornadas de trabalho extenuantes eram as mais frequentes. ${ }^{16}$

As demandas relacionadas ao cotidiano das fábricas não figuraram na pauta sistematizada pela direção das greves daquele ano. Absortas pelo sucesso do movimento, as lideranças da federação operária e do Comitê de Defesa Proletária dedicaram-se a formular resoluções e bases de acordo em itens que, para eles, levariam a sociedade a profundas transformações. Mesmo assim, em formas menos evidentes de organização, para além das barreiras colocadas 
pelos sindicatos, as reivindicações de direitos das mulheres tomaram maior fôlego e ocuparam sistematicamente a arena pública.

As ligas mantiveram-se fortes e atuantes nos tempos que se seguiram à mobilização de julho. Em reunião no Brás, discutiram o aumento de salário consentido pela Fábrica de Tecidos Ítalo-Brasileira, ${ }^{17}$ todavia, ao menos naqueles dias, parecia mais fácil obter aumento de vencimentos que demitir um mestre de oficina que faltasse com o respeito ou praticasse atos tidos como imorais.

Reivindicar respeito, que bem poderia ser uma referência a abusos sexuais cometidos por feitores e capatazes, tinha mais valor e estava mais ligado à experiência de classe das mulheres do que, até mesmo, os ideais de igualdade e emancipação, ao menos entre anarquistas. Maria Antônia Soares ao tentar descobrir a forma de "outorgar a verdadeira emancipação" às mulheres, nas colunas de A Plebe, afirmou que não bastava a independência econômica, nem a instrução, nem governo, sequer a igualdade de salários ou a liberdade. $\mathrm{O}$ voto, para ela, deixava esse conjunto de soluções ainda menos completo: "Esta coisa, que bastaria, por si só, talvez, para elevar moralmente a mulher e emancipá-la é o respeito". ${ }^{18}$

Não era raro que os jornais retratassem a atividade das ligas nos anos que se seguiram com destaque para participação de mulheres. A disputa interna ao movimento operário e a pressão exercida pelos poderes públicos, somadas à repressão policial conduziram a organização para sindicatos de ofício, mas as ligas não acabaram da noite para o dia. O aniversário de 1918 da Liga Operária do Brás contou com a presença de "numerosas e gentis senhoritas" e comemorou a vitória do pleito por aumento de salários. ${ }^{19}$ A Liga Operária da Mooca sempre convocava membros de "ambos os sexos" para as reuniões. ${ }^{20}$ As ligas se fundaram com princípios da Associação Internacional dos Trabalhadores (AIT) calcados na ideia de que a emancipação deveria ser feita pelos próprios trabalhadores e lançar bases para a criação de uma grande associação operária de resistência (Lopreato, 2000). A primeira liga havia se constituído na Mooca, meses antes do estopim da greve geral, já com centenas de membros. Na sequência, organizaram-se trabalhadores do Belenzinho e depois foram fundadas as ligas da Lapa, Água Branca, Brás, Cambuci, Bom Retiro, Vila Mariana e Ipiranga.

A participação das trabalhadoras na organização operária de 1917 é reconhecida em muitas pesquisas. Luigi Biondi aferiu a participação delas em diversos momentos, como membros dos núcleos de direção ou como engajadas nas paralisações e piquetes. A presença feminina era um dado em organizações 
por setores onde elas eram destacada maioria: em 1912, mulheres e meninas compunham quase $72 \%$ da força de trabalho do setor têxtil. ${ }^{21}$ Dessa forma, era de se supor um número grande de mulheres na Liga Operária do Ipiranga, que contava com cerca de 3 mil membros, 1.800 dos quais trabalhavam na fábrica de tecidos Nami Jafet. A atuação das ligas se alimentava da atividade das comissões de fábricas e conduzia as pautas de acordo com o cotidiano de trabalho.

Outras categorias, com considerável número de mulheres, ganharam força na organização operária durante os anos que se seguiram às greves. As cigarreiras, "maioria composta de pobres moças indefesas", definidas em A Plebe como uma das mais "exploradas da família operária", se organizaram em sindicato em 1919, e a negociação que entoaram com os patrões resultou em aumento de salário. ${ }^{22}$ Uma parte das trabalhadoras exercia seu trabalho remunerado nas chamadas "indústrias domiciliares", unidades produtivas domésticas compostas, por exemplo, por costureiras, geralmente sujeitas a condições de trabalho nada parecidas com as das fábricas e tampouco conhecidas do Estado e do movimento operário organizado. Ainda que nesses termos, em 1923 organizaram-se na União das Costureiras, embora estivessem desde 1919 reunidas na União das Costureiras e Alfaiates. ${ }^{23}$ Em 1921, as costureiras capitanearam curso de instrução para todas as operárias femininas por acreditarem que a emancipação da mulher na sociedade seria proveniente da educação e do fim do analfabetismo. ${ }^{24}$ Era dessa mesma forma que os colaboradores de $A$ Plebe pensavam a igualdade entre mulheres e homens na organização política que desempenhavam: a baixa capacitação das mulheres seria a causa da exploração que sofriam e da ausência delas nos espaços de decisão do movimento operário.

Seja por meio das ligas ou fora delas e dos sindicatos, a participação das mulheres na força de trabalho e na organização social, dita enfraquecida por alguns, se alastrou pelos anos 1920. A atenção dos donos de fábrica foi permanente: houve greve na Fábrica Paulistana, em 1921, na Fábrica Ipiranga, em 1923, e algumas paralisações nos demais estabelecimentos. Diante desse estado de mobilização, os empresários travaram uma aliança forte e contínua com o aparato policial e com o poder público. Na Companhia Fabril Paulistana, 12 mulheres foram demitidas por praticar agitação política entre as trabalhadoras em virtude da última greve realizada. Em São Bernardo, mais 12 perderam seus postos de trabalho pelo mesmo motivo. ${ }^{25} \mathrm{~A}$ organização patronal mantinha olhar diligente sobre elas. 


\section{DEPOIS DE 1917}

Como um dos resultados das greves de 1917, além do marco que significou para a classe trabalhadora, a classe patronal também passou a se organizar sistematicamente para evitar suas perdas financeiras e exercer pressão de forma mais contundente sobre os governos do estado e federal, principalmente naquilo que dizia respeito à aprovação de leis sociais. Dessa forma, o Centro dos Industriais de Fiação e Tecelagem (CIFT), fundado em 1919, promovia debates sobre organização do trabalho, tarifas, impostos e o próprio movimento operário por meio de suas circulares que tramitavam entre todos os donos de fábrica filiados à entidade. O CIFT mantinha sólida parceria com a polícia na vigilância de quem se projetava como "subversiva" ou "indesejável", muito antes mesmo da fundação da Delegacia de Ordem Política e Social (DOPS), em 1924. Entre as “indesejáveis” figurava a operária Maria Teófilo, expulsa da fábrica Mariângela em 30 de abril de 1920, que logo foi trabalhar na fábrica Luzitania e também de lá foi demitida por "atos reprováveis". ${ }^{26}$ Maria Teófilo e diversas outras pessoas compunham listas detalhadas que circulavam entre os donos de fábrica contendo o nome de trabalhadoras e trabalhadores com o objetivo de evitar a recontratação desses “indesejáveis". Eram até mesmo monitoradas aquelas que realizavam pequenos furtos ou entravam em confusão com colegas de trabalho, mas não seria possível aferir a justiça das acusações apenas pela fonte produzida pelo patronato que, vez ou outra, poderia considerar adequado demitir alguém por furto ou briga na intenção de se ver livre de um elemento agitador (Ribeiro, 1988). Apenas no ano de 1925, a lista de "indesejáveis" contém 36 nomes e, desses, 35 são acusados de roubo ou furto. Do total de demissões constam 22 mulheres.

Sabemos das greves que aconteceram nas fábricas de tecido em 1924 mais pela leitura das circulares patronais do que pela imprensa, visto que a repressão policial cuidou de empastelar a maior parte dos jornais que haviam circulado nos anos anteriores. Era o mesmo tempo em que as tensões entre uma parte do Exército e o governo de Artur Bernardes se agravaram. Um levante dos chamados "tenentes" tomou algumas estações de trem e foi violentamente reprimido, criando um clima de terror na cidade. A insurgência dessas forças era também movida pela contestação da concentração de poder nas mãos de grupos oligárquicos que se beneficiavam da fraca presença do Estado na tomada de decisões sobre os conflitos sociais (De Decca, 1994).

Ainda que seja possível saber pouco das mobilizações desse período e com alguma dificuldade, podemos propor uma leitura das fontes patronais a nos 
dizer sobre as relações de trabalho e a vida das mulheres. Naquele ano, América Montorso, urdideira (operária que trama o fio a partir do novelo) e a tecelã Ersília Montorso perderam seus trabalhos da fábrica Matarazzo do Belenzinho com o empregado da seção de estamparia João Montorso. ${ }^{27} \mathrm{O}$ mesmo já se passara com Palmyra Caffine e Angelina Caffine, demitidas do serviço da Companhia Fabril Paulistana na mesma leva de "indesejáveis". Cornelia Bagnini e Olga Bagnini foram acusadas de roubarem fios em espulas e dispensadas da fábrica em que trabalhavam. Com Manoel Sorita, Maria Sorita e Rosária Sorita foram desligados da Fábrica de Tecidos São Bernardo. Da fábrica Luzitania, foram demitidas como agitadoras, na mesma feita, Benedita Cerqueira e Italgina Cerqueira, operárias maçaroqueiras (operadoras de máquinas que torcem fios). As retorcedeiras (responsáveis pelo nivelamento dos tecidos) da fábrica Mariângela, Vittoria Billot e Giuseppina Billot, assim como Ângelo Billot, ficaram sem os postos de trabalho acusados de furto. Moradoras da Penha foram desligadas do serviço de uma só vez: Creonice Ferreira e Eliza Vollo, que viviam na Rua Guaiaúna, ambas na casa de número 20, acusadas de roubo com Maria dos Anjos, que morava no número 130 da mesma rua; Etelvina Prado Guimarães e sua filha Maria Prado Guimarães, moradoras da rua da Penha, foram demitidas da mesma fábrica Scarpa, por motivo de furto. Seja fora das ligas, ou ainda dos sindicatos, a atuação das mulheres a questionar as relações de trabalho a que estavam submetidas aparece sistematicamente em fontes cujo objetivo é policiar o que acontece dentro das fábricas. Essas fontes provêm, portanto, valiosas pistas sobre uma forma de sociabilidade largamente utilizada pelas mulheres e que não se encaixava, de antemão, nos padrões sindicais ou esperados: a família ou a vizinhança. A escolha da sociabilidade por esses dois critérios certamente promovia o conforto e alguma segurança para aquelas que têm sua honra questionada todo o tempo.

\section{JUSTIÇA PARA A CLASSE TRABALHADORA}

Enquanto paralisações e piquetes ainda aconteciam na cidade de São Paulo, as soluções para os conflitos que vieram à tona por meio das greves de julho de 1917 eram debatidas tanto no movimento operário, quanto na imprensa e no Parlamento. $\mathrm{O}$ trabalho de menores era um dos pontos centrais das discussões, não sem motivo, já que constituía uma das causas para a deflagração das greves. Dessa forma, a regulação do trabalho das crianças foi uma das maneiras pelas quais a classe trabalhadora expressou o seu envolvimento com a aprovação de leis. As atrocidades cometidas contra as crianças nos 
postos de trabalho fabril sequer terminariam com o ano de 1917. Damiano Cacciolito, em idade escolar, encostou para descansar na fábrica Penteado porque sentia dores de dente. Conforme registrou A Plebe, em 4 de novembro de 1922, fragilizado pela febre, foi devorado por cães a mando dos mestres. Seu enterro se tornou um protesto de homens e mulheres contra a exploração das crianças. Nem mesmo o interventor do estado de São Paulo sabia dizer sobre o regramento do trabalho de menores, mas, depois de julho de 1917, ficaria difícil ignorar o problema:

Os leitores devem estar lembrados de que uma das reclamações apresentadas pelos operários durante as greves de julho, era relativa aos trabalhos de menores nas fábricas. Felizmente, agora, a Diretoria do Serviço Sanitário resolveu agir e está fazendo distribuir um aviso por todas as oficinas e fábricas, lembrando aos respectivos proprietários algumas das disposições do Regulamento Sanitário do Estado, a respeito do trabalho de menores.

Resta ver, ainda, se os industriais que se recusarem a obedecer estas disposições da lei serão punidos de fato, pois até agora as multas não têm sido cobradas. ${ }^{28}$

Estimava-se que uma em cada três crianças morria em decorrência da brutalidade das relações de trabalho e, de acordo com Nicanor Nascimento, no Brasil, não havia legislação operária como "meio de segurança" para amparar as classes trabalhadoras. ${ }^{29}$ As greves, certamente, impulsionaram a reforma dos códigos também em 1918, segundo a qual menores não deveriam trabalhar em indústrias de bebidas alcóolicas, lidar com máquinas pesadas e executar trabalhos que produzissem fadiga demasiada. O regulamento sanitário também estabelecia que menores de 18 anos e mulheres não deveriam trabalhar à noite. A licença-maternidade aparecia pela primeira vez nos regramentos do estado de São Paulo, e as leis para higiene do trabalho determinavam que as mulheres não poderiam trabalhar na indústria durante o último mês de gravidez e o primeiro do puerpério. O Código Sanitário legislava apenas sobre o trabalho e sobre a higiene no estado de São Paulo.

Para muitos, o Brasil era uma "página em branco" sobre as questões das mulheres e da infância, embora fossem reconhecidos os empenhos regulatórios dos códigos sanitários. Pouco tempo depois, tais páginas vazias passariam a ser escritas com projetos de instalação de creches, licença-maternidade e proibição do trabalho noturno de mulheres, questões que orientaram o debate travado pelos parlamentares da Comissão de Constituição e Justiça, particularmente preocupada em envolver as demandas emergidas dos conflitos sociais 
de 1917, "despertados violentamente pela veemência tumultuosa das reivindicações do proletariado, pelo apelo vibrante do exército de operários que reclamam justas concessões e razoáveis vantagens”. Registrava-se ser mesmo um momento de mudança para as questões afetas às mulheres, que já tinham recebido alguma preocupação legislativa por parte do deputado Maximiano Figueiredo, mas sem a mesma notoriedade que o ano de 1917 proporcionou: "Agora, porém, parece que os dirigentes compenetraram-se afinal de que não é possível adiar por mais tempo o dever social inelutável de proteger e preservar a saúde das mães operárias e de seus filhos na vida uterina e durante a lactância". ${ }^{30}$

Foram cinco os projetos de lei apresentados pelo deputado Maurício de Lacerda, ainda em julho de 1917, três dos quais abordavam o trabalho de mulheres e crianças: o Projeto n. 125, de 16 jul. 1917, sobre o trabalho feminino, o Projeto n. 135, de 24 jul. 1917, sobre criação de creches em estabelecimentos industriais, e o Projeto n. 137, de 18 jul. 1917, sobre a criação de contratos de aprendizagem. Até 1920, todos foram discutidos pela Comissão de Legislação Social, formada em 1918. Mais tarde, as medidas propostas por Maurício de Lacerda seriam discutidas no escopo do Projeto n. 284, que ficou conhecido como Código do Trabalho e reunia as proposições sobre o tema.

Desde o princípio, ao se pensar a instalação de uma legislação para o trabalho, o que estava em jogo era remediar a questão social e a proteção do trabalhador e sua família. Isso significava dizer que se construía a concepção do trabalho livre, como matéria de direitos, de forma nada neutra - conjugava-se a noção de que as prerrogativas masculinas estavam enraizadas na existência de uma família que dependia do trabalho da mulher em casa e na criação dos filhos. A proteção da força de trabalho, em vista de uma legislação pensada como fator de ordem sanitária e moral, envolvia o futuro da raça humana e a reprodução e conservação da própria força de trabalho. Foi por dentro desses aspectos que se forjou o pensamento sobre a proteção do trabalho das mulheres no Parlamento (Gomes, 1979).

O tema da igualdade entre mulheres e homens esteve presente na luta dentro das fábricas, nos sindicatos e dentro do movimento operário. Essa investigação proporcionou a compreensão de formas diversas de pressão por direitos, o que garantiu a entrada dos temas afetos às condições de vida das trabalhadoras no Parlamento e no debate geral da luta por direitos. O malogro na aprovação de um código global do trabalho nos anos 1920, muitas vezes criticado por ser a Comissão de Legislação Social morosa nos debates ou não ter legitimidade para legislar nacionalmente, criaria parâmetros definitivos 
para o direito do trabalho que seriam retomados diversas vezes em momentos posteriores, como no caso da aprovação do Decreto do Trabalho das Mulheres, em 1932. A partir das Greves de 1917 e dos trabalhos parlamentares, nos anos subsequentes, a noção de que é preciso legislar sobre a mulher trabalhadora torna-se incontornável na formulação de leis e no entendimento sobre justiça social no Brasil.

\section{REFERENNCIAS}

BATALHA, Cláudio. O movimento operário na Primeira República. Rio de Janeiro: Zahar, 2000.

BIONDI, Luigi. Classe e nação: trabalhadores socialistas italianos em São Paulo, 18901920. Campinas: Ed. Unicamp, 2011.

A Greve Geral de 1917 em São Paulo e a imigração italiana: novas perspectivas. Cadernos AEL, v.15, n.27, p.263-306, 2009.

COBBLE, Dorothy Sue. The Other Women's Movement: Workplace, Justice and Social Rights in Modern America. Princeton, NJ: Princeton University Press, 2004.

DE DECCA, Edgar S. 1930: O silêncio dos vencidos. (1981). 6.ed. São Paulo: Brasiliense, 1994.

FAUSTO, Boris. Trabalho urbano e conflito social. Rio de Janeiro: Difel, 1979.

GOMES, Ângela de Castro. Burguesia e Trabalho: política e legislação social no Brasil, 1917-1937. Petrópolis: Vozes, 1979.

HALL, Michael. Entre a etnicidade e a classe em São Paulo. In: CARNEIRO, Maria Luiza Tucci; CROCI, Federico; FRANZINA, Emilio. História do trabalho e histórias de imigração. São Paulo: Edusp; Fapesp, 2010.

. Immigration and the Early São Paulo Working Class. Jahrbuch für geschichte von staat, wirtschaft und gesellschaft Lateinamerikas, v.12, 1975.

HALL, Michael; PINHEIRO, Paulo Sérgio. A Classe Operária no Brasil (1889-1930). São Paulo: Alfa Ômega, 1979.

KESSLER-HARRIS, Alice. Gendering Labour History. Champaign, IL: University of Illinois Press, 2007.

LOPREATO, Christina. O espírito da revolta: a greve geral anarquista de 1917. São Paulo: Annablume; Fapesp, 2000.

NEGRO, Antonio Luigi; FONTES, Paulo. Trabalhadores em São Paulo: ainda um caso de polícia. O acervo do DEOPS paulista e o movimento sindical. In: AQUINO, Maria Aparecida de (Org.) No coração das trevas: o DEOPS/SP visto por dentro. São Paulo: Arquivo do Estado; Imprensa Oficial do Estado, 2001.

PAOLI, Maria C. Labour, Law and the State in Brazil. PhD Dissertation - Birkbeck College, University of London. London, 1988. 
PENA, Maria Valéria J. Mulheres e trabalhadoras: presença feminina na constituição do sistema fabril. Rio de Janeiro: Paz e Terra, 1981.

PERROT, Michelle. As mulheres ou os silêncios da História. Florianópolis: Edusc, 2005.

RIBEIRO, Maria Alice R. Condições de trabalho na indústria têxtil paulista (18701930). Campinas: Hucitec; Ed. Unicamp, 1988.

SILVA, Fernando Teixeira; CORRÊA, Larissa. The Politics of Justice: Rethinking Brazil's Corporatist Labor Movement. Labor - Studies in Working-Class History of the Americas, v.13, n.2, 2016.

TOLEDO, Edilene. Travessias revolucionárias: ideias e militantes sindicalistas em São Paulo e na Itália (1890-1945). Campinas: Ed. Unicamp, 2004.

WOLFE, Joel. Working Women, Working Men: São Paulo and the Rise of Brazil's Industrial Working Class, 1900-1955. London: Duke University Press, 1993.

\section{NOTAS}

${ }^{1}$ Este artigo apresenta parte dos resultados de minha tese de doutorado defendida em 2016, que contou com financiamento da Fundação de Amparo à Pesquisa do Estado de São Paulo (Fapesp).

${ }^{2}$ O Combate, 13 nov. 1917, e O Combate, 3 jan. 1919.

${ }^{3}$ Ainda que a colaboração de mulheres fosse pouco frequente no jornal A Plebe, Maria Antônia Soares, da Liga Operária do Belenzinho, era a assinatura feminina mais assídua. Ela teria também colaborado para o jornal $O$ Grito Operário, ligado aos operários da construção civil, entre 1919 e 1920. Em 1921, recebeu um artigo em sua homenagem assinado pela sigla "I.R." ressaltando sua trajetória heroica por "reclamar para o homem a nobilitação ao trabalho e aos prazeres da vida na equidade”. A Plebe, 12 mar. 1921.

${ }^{4}$ Desconto no salário de trabalhadores italianos para contribuírem com o Comitê Italiano Pró Pátria no intuito de enviar donativos à guerra. No estado de São Paulo, no período, havia 1.500 famílias italianas que tinham, ao menos, um componente no front de guerra. Donos de fábrica, de grande e pequeno porte, organizavam o recolhimento e o envio de donativos (BIONDI, 2011). Para Michael Hall, a cobrança da comissão era um forte elemento da tensão existente entre imigrantes italianos e industriais da mesma origem (HALL, 2010).

${ }^{5}$ Correio Paulistano, 30 jun. 1917.

${ }^{6}$ O Combate, 13 jul. 1917.

${ }^{7}$ O Combate, 12 jul. 1917.

${ }^{8}$ O Combate, 18 jul. 1917.

${ }^{9}$ Lei n. 240, de 4 set. , 1893 e Lei n. 432, de 3 ago. 1896. Ver também Lei n. 2.141, de 14 nov. 1911, que regulamentou o Serviço Sanitário no estado de São Paulo. 
${ }^{10}$ O Combate, 20 jul. 1917.

${ }^{11}$ O Combate, 17 out. 1917, e A Plebe, 4 out. 1919.

${ }^{12}$ O Combate, 27 out. 1917.

${ }^{13}$ O Combate, 24 out. 1917.

${ }^{14}$ O Combate, 26 out. 1917.

${ }^{15}$ O Combate, 17 ago. 1917.

${ }^{16}$ A Plebe, 18 ago. 1917.

${ }^{17}$ O Combate, 14 ago. 1918.

${ }^{18}$ A Plebe, 27 nov. 1920.

${ }^{19}$ O Combate, 2 ago. 1918, e O Combate, 14 ago. 1918.

${ }^{20}$ O Combate, 13 set. 1918.

${ }^{21}$ Boletim do Departamento Estadual do Trabalho, v.6, n.2, p.138-139, 1913.

${ }^{22}$ A Plebe, 12 jul. 1919.

${ }^{23}$ A Plebe, 21 jun. 1919, 16 out. 1919 e 18 jun. 1921. Sobre a fundação da União das Costureiras: A Plebe, 4 ago. 1923.

${ }^{24}$ A Plebe, 25 jun. 1921.

${ }^{25}$ AEL. Circular CIFT n. 26, 8 jun. 1921, e AEL. Circular CIFT, n. 106, 26 maio 1922.

${ }^{26}$ AEL. Circular CIFT, n. 19, 21 maio 1921.

${ }^{27} \mathrm{O}$ jornal A Plebe acompanhou as greves do setor de tecido. A Plebe, 15 mar. 1924. Circular CIFT, n. 304, 19 mar. 1924. Para os demais casos, ver estas referências: AEL. Circular CIFT, n. 26, 8 jun. 1921; Circular CIFT, n. 41, 27 jun. 1921; Circular CIFT, n. 84, 21 jan. 1922; Circular CIFT, n. 419, 10 fev. 1925; AEL. Circular CIFT, n. 514, 28 ago. 1925.

${ }^{28}$ A declaração do interventor está em O Combate, 20 jul. 1917. O editorial de O Combate foi publicado em 29 nov. 1917.

${ }^{29}$ O Combate, 13 maio 1918. Nicanor Nascimento foi deputado federal pelo Distrito Federal entre 1911 e 1917 e entre 1924 e 1926. Esteve ligado a grupos socialistas e procurava difundir as pautas do movimento operário do período.

${ }^{30}$ Todas as aspas estão em: O Combate, 27 set. 1917.

Artigo recebido em 25 de maio de 2017. Aprovado em 6 de outubro de 2017. 